\title{
Posicionamento dos representantes dos usuários no Conselho Estadual de Saúde da Bahia diante do agravamento do subfinanciamento do SUS em 2016-2018
}

\section{Positioning of user representatives in the State Health Council of Bahia in view of the worsening of SUS sub-financing in}

\section{6-2018}

\author{
Aissa Siqueira de Morais ${ }^{a}$ \\ (D) https://orcid.org/0000-0001-9516-5075 \\ E-mail: moraisaissa®gmail.com

\section{Carmen Fontes Teixeirab} \\ (D) https://orcid.org/0000-0002-8080-9146 \\ E-mail: carmentळufba.br \\ aniversidade Federal da Bahia. Faculdade de Medicina da \\ Bahia. Salvador, BA, Brasil. \\ buniversidade Federal da Bahia. Instituto de Humanidades, \\ Artes e Ciências. Salvador, BA, Brasil.
}

\section{Correspondência}

Aissa Siqueira de Morais

Rua Macedo de Aguiar, 229, casa 25. Salvador, BA, Brasil. CEP 41740-085.

\section{Resumo}

O objetivo desse trabalho é analisar o posicionamento dos representantes dos usuários no Conselho Estadual de Saúde da Bahia (CES-BA) diante das decisões do Governo Federal relativas ao financiamento do Sistema Único de Saúde (SUS) no período 2016-2018. O referencial teórico se baseia na noção de participação incorporada no arcabouço jurídico político do SUS, que institui a criação de Conselhos de Saúde e a realização de Conferências de Saúde como espaços de formulação, monitoramento e avaliação de políticas de saúde nos diversos níveis organizativos do sistema. A coleta de dados foi realizada por meio de revisões documentais e entrevistas aos representantes do segmento usuários no conselho. Os resultados contemplam a caracterização do perfil político-associativo das entidades representadas no CES-BA e o posicionamento dos conselheiros sobre as mudanças no financiamento do SUS no período 2016-2018. Discute-se a baixa representatividade de alguns grupos populacionais no CES-BA e a percepção acerca da Emenda Constitucional 95 e da influência dos partidos políticos na dinâmica dos conselhos. A conclusão ressalta a importância relativa da qualificação técnica diante da experiência acumulada pelos conselheiros e a necessidade de articulação destes com as bases sociais que pretendem representar, especialmente na atual conjuntura política brasileira.

Palavras-chave: Política de Saúde; Sistema Único de Saúde; Participação Social em Saúde; Financiamento. 


\section{Introdução}

The objective of this study is to analyze the orientation of user representatives in the Health Council of the Bahia (CES-BA) in face of the decisions of the Federal Government finance the Unified Health System (SUS) in the period 2016-2018. The theoretical reference is based on the notion of participation incorporated in the SUS legal code, which instituted Health Councils and the holding of Health Conferences as spaces for formulating, supervising and evaluating health policies at the various organizational levels of the system. Data were collected via document review and interviews with representatives of the segment "users" at CES-BA. The results include the characterization of the political-associative profile of the entities represented in the State Health Council and the orientation of the counselors on changes in SUS financing in the 2016-2018 period. It discusses the low representativeness of some population groups at CES-BA and the perception of councilors about Constitutional Amendment 95 and the influence of political parties on the dynamics of councils. The conclusion shows the relative importance of technical qualification in the face of the experience accumulated by the councilors and the need to articulate them with the social bases they intend to represent, especially in the current political situation of the country.

Keywords: Health Policy; Brazilian National Health System; Social Participation in Health; Financing.
A "participação social em saúde" foi incorporada na Legislação Orgânica do SUS - Lei no 8.080/1990 (Brasil, 1990a) - pela Lei no 8.142/1990 (Brasil, 199ob), que respalda a criação de conselhos e a realização das conferências de saúde nas diversas esferas do governo. A criação e expansão dos conselhos de saúde passaram a ocorrer nas décadas seguintes, estimuladas pela implementação das Normas Operacionais Básicas do SUS (NOB o1/93 e NOB/96), que as estabeleceram como necessárias para o repasse de recursos do Governo Federal - Ministério da Saúde - aos estados e municípios, somada à existência de conselhos estaduais e municipais com funcionamento regular (Brasil, 1993, 1996) e composição paritária, sendo 50\% de representantes dos gestores, trabalhadores de saúde e prestadores de serviços e 50\% de representantes dos usuários (Carvalho, 1995; Costa; Noronha, 2003).

Os conselhos de saúde, portanto, são órgãos de caráter permanente, com a função de formular estratégias e mecanismos de controle das políticas de saúde em sua respectiva instância (Brasil, 199ob). A criação de conselhos municipais de saúde e a institucionalização dos conselhos estaduais e nacionais de saúde têm sido acompanhadas de inúmeras atividades de capacitação dos conselheiros, bem como da realização de pesquisas acerca dos limites e possibilidades de sua atuação (Temoteo, 2016).

Mais recentemente, a situação política no Brasil se agravou a partir do impeachment da ex-presidente Dilma Rousseff, que alguns analistas políticos têm denominado "golpe jurídico-parlamentar e midiático" (Miguel, 2016). A tomada do poder pelo então vice-presidente, Michel Temer, exacerbou valores e práticas antidemocráticas e desdobrou em decisões políticas voltadas a implementar um "projeto de governo" baseado em perspectiva neoliberal, que implica na redução do papel do Estado na área de políticas sociais (Virgens; Silveira, 2016) e portanto não valoriza uma política de saúde focada em garantir a universalidade, integralidade e equidade da atenção, privilegiando o setor privado (Paim, 2018).

Nessa perspectiva, o governo Temer agravou um processo de "desmonte" da política adotada 
na Lei Orgânica da Saúde ao tornar constitucional o subfinanciamento crônico do SUS com a aprovação da Emenda Constitucional 95 (EC95), que congela os gastos sociais por 20 anos na saúde e educação (Noronha et al., 2018; Paim, 2018).

Para evidenciar os elementos que compõem este processo de "desmonte", construímos uma linha do tempo (Figura 1) de alguns fatos políticos do período 2016-2018. Os fatos dispostos na parte superior referem-se a propostas apresentadas pelo Ministério da Saúde - por exemplo, "planos populares de saúde”, que corroboram a justificativa de inviabilidade financeira para um sistema público de saúde (Torres; Reis, 2016); aprovação da EC95; a nova Política Nacional de Atenção Básica, que, dentre tantas alterações, possibilita outras modalidades de atenção básica além da Estratégia Saúde da Família (Oaps, 2017), bem como mudanças na política de saúde mental que violam os princípios da Reforma Psiquiátrica (Dominguez, 2018) e cortes no Bolsa Família, um importante programa social que contribuiu para a redução da pobreza, auxiliando milhares de famílias a garantir o mínimo de condições de subsistência (Rocha, 2018).

\section{Figura I - Linha do tempo: eventos relevantes no processo político em saúde 2016-2018}

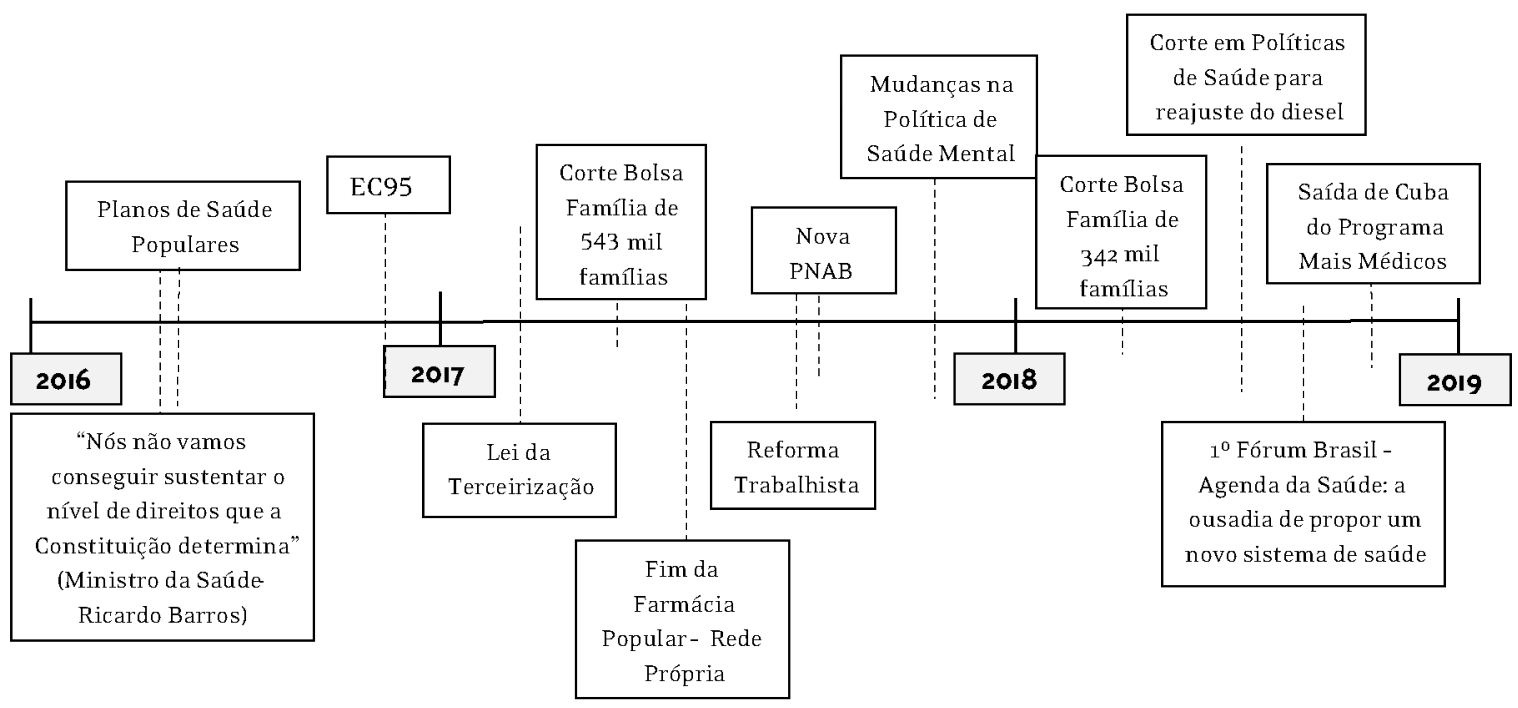

EC95: Emenda Constitucional 95; PNAB: Política Nacional de Atenção Básica.

Na parte inferior da linha do tempo colocamos alguns eventos mais gerais que compõem o cenário econômico e político, como a aprovação da Lei da Terceirização (Brasil, 2017a) e da Reforma Trabalhista (Brasil, 2017b), assim como o $1^{\circ}$ Fórum da Federação Brasileira de Planos de Saúde, com participação do Ministério da Saúde, que propôs a "reformulação" do SUS pela iniciativa privada (Governo..., 2018). 0 ano de 2018 culmina com a eleição de Jair Bolsonaro que, ao fazer comentários desrespeitosos aos médicos cubanos que trabalhavam no país, levou o governo cubano a solicitar o fim da cooperação Cuba/Brasil pelo Programa Mais Médicos (Reis, 2018).
Considerando as mudanças que vêm ocorrendo no cenário político brasileiro e os efeitos desse processo na política de saúde, especificamente na condução e financiamento do SUS, torna-se necessário investigar o posicionamento das entidades representadas nas diversas instâncias de participação e controle social do SUS. Afinal, foram movimentos sociais e entidades da sociedade civil organizada os principais responsáveis pela consolidação de pilares constituintes dos direitos sociais e do direito à saúde em particular (Paim, 2018); logo, seu posicionamento diante do momento político atual é de fundamental interesse, sobretudo quando essas entidades fazem parte de um mecanismo de participação institucionalizado representando 
os usuários do SUS. Nesse sentido, o objetivo do presente estudo é analisar o posicionamento dos representantes dos usuários no Conselho Estadual de Saúde da Bahia (CES-BA) diante das decisões do Governo Federal relativas ao financiamento do SUS no período 2016-2018.

\section{Metodologia}

Trata-se de uma pesquisa exploratória, de caráter descritivo e analítico, com base na análise de documentos e realização de entrevistas. Os primeiros foram extraídos de sites, blogs e da página no Facebook das entidades que compõem o segmento usuários do CES-BA. As informações obtidas foram sistematizadas em uma matriz que contém: (1) informações gerais acerca da entidade; (2) objetivos da entidade; (3) base social da entidade (características dos filiados/associados); (4) propostas específicas em relação à saúde (política de saúde e SUS); e (5) ações desenvolvidas no período 2016-2018.

A partir da relação das entidades foram identificados os titulares e seus suplentes, obtendo-se com a secretaria do conselho seus e-mails e números de telefone. Diante da dificuldade de obter respostas via e-mail, após três tentativas, foram enviadas mensagens via WhatsApp e/ou ligações telefônicas para todos os integrantes do segmento dos usuários (16 titulares e 15 suplentes). Em uma última tentativa de alcançar o número estipulado de 16 informantes, foram feitas quatro visitas a reuniões do conselho para contatar pessoalmente os conselheiros. Ao final, conseguiu-se a anuência de nove titulares e cinco suplentes, o que se aproxima do número planejado.

As entrevistas foram gravadas e realizadas com base em um roteiro semiestruturado após a leitura e assinatura, em duas vias, do Termo de Consentimento Livre e Esclarecido pelos entrevistados. As questões postas nesse roteiro visaram obter informações acerca do posicionamento político da entidade (representada pelo entrevistado) diante das medidas governamentais com relação ao financiamento do SUS no período 2016-2018, especialmente a da EC95, bem como informações complementares acerca do perfil da entidade e sua agenda política no que diz respeito ao SUS.
A análise das informações obtidas dos sites e das entrevistas buscou, inicialmente, caracterizar o perfil político e associativo das entidades que compõem o segmento dos usuários do CES-BA na gestão 2016-2018, sistematizando os seguintes aspectos: (1) objetivos da entidade; (2) base social da entidade (características dos filiados/associados); e (3) propostas específicas em relação à saúde. Em seguida, foi feito o processamento e análise das respostas coletadas nas entrevistas, com base na leitura das transcrições realizadas por uma das pesquisadoras, buscando-se identificar os "núcleos de sentido" (Bardin, 2011) e organizar as informações da visão dos entrevistados sobre o financiamento do SUS.

O projeto seguiu as diretrizes e normas regulamentadoras de pesquisas envolvendo seres humanos previstas na Resolução nº 466/2012, do Conselho Nacional de Saúde (CNS), tendo sido aprovado no Comitê de Ética em Pesquisa da Faculdade de Medicina da Bahia com o parecer $n^{0} 3.016 .670$ e apresentado e aprovado na $29^{a}$ Reunião Extraordinária do CES-BA. Durante sua execução, foram garantidos os princípios éticos da pesquisa científica, inclusive a participação voluntária dos entrevistados, mediante assinatura do Termo de Consentimento Livre e Esclarecido.

\section{Resultados}

\section{Composição do segmento usuário no CES-BA}

Inicialmente, tratamos de analisar a composição do CES-BA na gestão 2016-2018, ponto de partida para a análise do posicionamento desses representantes em relação às mudanças no financiamento do SUS na atual conjuntura. O CESBA é composto atualmente por 32 representantes, respeitando a paridade determinada na Lei no 8.142/199o (Brasil, 199ob) e na Resolução CNS no 453/2012 (Brasil, 2012), que trata da organização dos conselhos - 16 entidades (metade) são representantes do segmento dos usuários. A composição desse segmento no CES para a gestão 2016-2018 está explicitada no Quadro 1, sendo, portanto, 16 conselheiros(as) titulares e 15 suplentes. 


\section{Quadro I - Composição segmento dos usuários Conselho Estadual de Saúde da Bahia (2016-2018)}

\begin{tabular}{|c|c|}
\hline Titulares & Suplentes \\
\hline \multicolumn{2}{|l|}{ Representantes estaduais do Fórum de Entidade de Patologias (4) } \\
\hline $\begin{array}{l}\text { Associação Baiana das Pessoas com Doença Falciforme (Abadfal) } \\
\text { Grupo Vontade de Viver, de Apoio aos Portadores de Hepatites } \\
\text { Virais } \\
\text { Movimento de Reintegração das Pessoas Atingidas pela } \\
\text { Hanseníase (Morhan) } \\
\text { Núcleo Assistencial para Pessoas com Câncer (Naspec) }\end{array}$ & $\begin{array}{l}\text { Centro de Estudo, Prevenção e Apoio aos Portadores de LER/ } \\
\text { DORT (Ceapler) } \\
\text { Rede Nacional de Pessoas Vivendo com HIV eAIDS } \\
\text { (RNP+Brasil) } \\
\text { Grupo de Prevenção à Prevenção à Aids (Gapa) } \\
\text { Associação de Defesa dos Pacientes Crônicos Renais do } \\
\text { Estado da Bahia }\end{array}$ \\
\hline \multicolumn{2}{|l|}{ Representantes estaduais do Fórum de Pessoas com Deficiência (2) } \\
\hline $\begin{array}{l}\text { Associação Baiana de Deficientes Físicos (Abadef) } \\
\text { Associação das Pessoas com Albinismo na Bahia (Apalba) }\end{array}$ & $\begin{array}{l}\text { Associação Baiana de Deficientes Físicos (Abadef) } \\
\text { Associação Metamorfose Ambulante de Usuários e } \\
\text { Familiares do Serviço de Saúde Mental (Amea) }\end{array}$ \\
\hline \multicolumn{2}{|c|}{$\begin{array}{l}\text { Representante estadual de entidades congregadas em federações e associações patronais urbanas e/ou rurais, exceto entidades } \\
\text { patronais da área da saúde ( } 1 \text { ) }\end{array}$} \\
\hline Federação das Indústrias do Estado da Bahia (Fieb) & Federação das Indústrias do Estado da Bahia (Fieb) \\
\hline \multicolumn{2}{|l|}{ Representante estadual do Fórum de Entidades Religiosas ( 1 ) } \\
\hline $\begin{array}{l}\text { Conferência Nacional dos Bispos do Brasil - Regional Nordeste } \\
3 \text { Bahia e Sergipe (CNBB) }\end{array}$ & $\begin{array}{l}\text { Conferência Nacional dos Bispos do Brasil - Regional } \\
\text { Nordeste } 3 \text { Bahia e Sergipe (CNBB) }\end{array}$ \\
\hline \multicolumn{2}{|c|}{ Representante estadual do Fórum de Mulheres Organizadas em Saúde (I) } \\
\hline União Brasileira de Mulheres (UBM) & $\begin{array}{l}\text { Rede Nacional Feminista de Saúde, Direitos Sexuais e } \\
\text { Direitos Reprodutivo }\end{array}$ \\
\hline \multicolumn{2}{|c|}{$\begin{array}{l}\text { Representantes estaduais de entidades congregadas em centrais e federações de trabalhadores urbanos e rurais, exceto } \\
\text { entidades da área da saúde (3) }\end{array}$} \\
\hline $\begin{array}{l}\text { Central dos Trabalhadores e Trabalhadoras do Brasil (СТВ) } \\
\text { Federação dos Bancários dos Estados de Sergipe e Bahia (Feeb) } \\
\text { Central Única dos Trabalhadores (CUT) }\end{array}$ & $\begin{array}{l}\text { Federação dos Trabalhadores e Trabalhadoras na } \\
\text { Agricultura do Estado da Bahia (Fetag-BA) } \\
\text { Central Única dos Trabalhadores (CUT) }\end{array}$ \\
\hline \multicolumn{2}{|c|}{ Representante estadual do Fórum de Entidades de Aposentados e/ou Pensionistas ( I) } \\
\hline $\begin{array}{l}\text { Associação dos Aposentados e Pensionistas da Previdência } \\
\text { Social da Bahia (Asaprev)/Casa do Aposentado }\end{array}$ & $\begin{array}{l}\text { Associação Habitacional, Crédito, Financeiro, Esporte, } \\
\text { Cultura, Lazer e Formação Profissionalizantes dos } \\
\text { Trabalhadores e Trabalhadoras do Ramo da Seguridade } \\
\text { Social na Bahia (Afoshaclass-BA) }\end{array}$ \\
\hline \multicolumn{2}{|l|}{ Representante estadual do Fórum de Combate à Violência (I) } \\
\hline $\begin{array}{l}\text { Centro Afro de Promoção e Defesa da Vida Padre } \\
\text { Ezequiel (Capdever) }\end{array}$ & $\begin{array}{l}\text { Centro Afro de Promoção e Defesa da Vida Padre } \\
\text { Ezequiel (Capdever) }\end{array}$ \\
\hline \multicolumn{2}{|l|}{ Representante estadual de Populações Indígenas ou Quilombolas ( I) } \\
\hline $\begin{array}{l}\text { Associação Cultural Ambientalista dos Índios Tupinambá } \\
\text { de Olivença }\end{array}$ & $\begin{array}{l}\text { Associação Cultural Ambientalista dos Índios Tupinambá } \\
\text { de Olivença }\end{array}$ \\
\hline \multicolumn{2}{|c|}{ Representante estadual do Fórum de Entidades do Movimento Antirracista ( 1 ) } \\
\hline Instituto Kutala 'Nleeke & União de Negros pela Igualdade (Unegro) \\
\hline
\end{tabular}

Fonte: site do CES-BA.'

1 Disponível em: <https://bit.ly/38HLRBA>. Acesso em: 10 nov. 2018. 
Dentre os conselheiros entrevistados, nove eram do sexo masculino e cinco do sexo feminino; no quesito raça/cor, sete dos entrevistados identificam-se como brancos, seis pardos/pretos e um indígena; destes, oito possuíam ensino superior completo, cinco ensino superior incompleto e um ensino técnico. As idades dos entrevistados varia entre 39 e 75 anos, já o tempo de participação no CES-BA foi, em média, seis anos.

Nota-se no Quadro 1 que, as entidades representantes de grupos de patologias são expressivas no contexto da saúde na Bahia, elas têm como objetivo central a prevenção/acompanhamento da respectiva patologia, bem como buscam reunir as pessoas para auxiliá-las no acesso à informação e serviços de saúde, emprego e garantia de direitos trabalhistas (benefícios/aposentadoria). Já as entidades organizadas por etnia, gênero ou religião atuam em diferentes frentes, mas costumam confluir em pautas contra o racismo, violência de gênero e com atuação junto às comunidades mais pobres. As entidades relacionadas à organização da classe trabalhadora enfatizam a luta por direitos trabalhistas, inserção no mercado de trabalho, sendo que a pauta comum no período estudado foi a luta contra as reformas trabalhista e da previdência. De modo geral, as análises documentais e das entrevistas evidenciaram um reduzido debate acerca do SUS na agenda dessas entidades, apesar de algumas terem sido estimuladas e participado de debates em defesa do SUS devido ao seu panorama entre 2016-2018.

Vale ressaltar que, não há representações de entidades de defesa do consumidor, organizações de moradores, nem entidades vinculadas ao movimento ambientalista. Constata-se também a ausência de entidades que representem as comunidades quilombolas, LGBTQIA+ e de religiões diferentes da católica (evangélicas, de matriz africana), dificultando que suas necessidades sejam consideradas nas políticas de saúde do estado. Percebe-se que na composição dos titulares e suplentes há uma repetição de entidades, ou seja, uma mesma ocupa a titularidade e suplência daquela representação. Isso ocorre nos seguintes casos: representação do fórum de pessoas com deficiência, federações e associações patronais urbanas e/ou rurais, fórum de entidade religiosa, fórum de combate à violência e na representação de populações indígenas ou quilombolas.

\section{Posicionamento diante do (des)financiamento do SUS}

Apesar dos graus diversos de aproximação com o tema, os entrevistados compreendem que há um subfinanciamento no SUS, trazem em suas falas que tal processo é crônico e já acontece há um tempo, dando a entender que isso já existia e que, na conjuntura atual, tem piorado. Entretanto, observa-se que os conselheiros tiveram dificuldade de expressar suas percepções acerca das mudanças que ocorreram no período 2016-2018 no financiamento do SUS, porém, quando perguntados diretamente sobre a EC95, parte deles reconhecia o tema.

Assim, de 14 entrevistados, 12 informaram ter participado do debate sobre esse tema no CES e posicionaram-se contra a EC95, por compreenderem que tal medida desestrutura ainda mais um sistema que já vive em condição de subfinanciamento. Para um dos entrevistados, inclusive, tal medida representou ainda mais uma aproximação com a agenda do capital, afastando o SUS da agenda do social (E11).

Nesse contexto, as entidades contrárias à EC95 somaram-se a um movimento nacional de mobilização contra esta emenda, organizado pelo CNS, com recolhimento de assinaturas para a construção de um abaixo-assinado que foi entregue em Brasília, e participaram da marcha que ocorreu na capital do Distrito Federal contra a EC, dentre outras mobilizações.

A gente mobilizou as entidades do movimento nacional e aqui na Bahia para a coleta de assinaturas, nós temos uma Ação Direta de Inconstitucionalidade que a gente está apoiando como Conselho Nacional de Saúde, para colocar abaixo a EC95. (E1)

$O$ desmonte houve, e a gente tentou reverter através de mobilizações de rua, grandes mobilizações de trabalhadores, aquela grande mobilização em Brasília [...] você limitar algo que 
já está limitado, mexer com financiamento, isso foi algo impactante. (Е3)

O entrevistado cinco relata como foi a experiência de levar o debate sobre a EC95 para as pessoas que compõem sua entidade, ressaltando que a população já percebia desmontes no SUS anterior à aprovação da EC, o que dificultou a percepção das pessoas sobre o que se altera a partir da emenda:

Mas émuito complexo, porque alguns impactos que as pessoas falam ou diziam que iam acontecer já estavam acontecendo, mesmo sem Emenda. A diminuição, o sucateamento do SUS, então a população tem enxergado isso de alguma forma. Parte diz: olha pode atingir a gente, mas não sentiu o impacto. $\left(\mathrm{E}_{5}\right)$

Apenas um dos entrevistados aponta a necessidade de se retirar alguns recursos do Ministério da Saúde, que ele considera "gordura", ou seja, supérfluos. Cita que percebe a discussão da EC95 como "tendenciosa", atribuindo a ênfase desse tema a "conselheiros vinculados ao PT" e, por admitir não ter informações acerca da emenda via “fontes seguras", preferiu não se aproximar da discussão nem se posicionar sobre o tema.

o que eu sei é que existe muitas coisas no Ministério da Saúde que deveria ser cortado, deveria cortar essa gordura. Dinheiro gastado em vão [...] eu acho que não pode ficar livre não, tem tanta roubalheira por aí [...] o pessoal quer tudo, mas não pode ser tudo... agora eu acho também que deveriam também fazer com outros Ministérios, não só com o Ministério da Saúde. Talvez eles acharam que era onde estava havendo mais desperdício, mas eu não tenho mais informações sobre isso e o pessoal é tendencioso, não quer saber, aí eu me afasto, minha posição é essa. (E12)

Parte dos entrevistados cita problemas, como falta de profissionais, dificuldades de acesso a exames de alta complexidade e a medicamentos, instalações precárias dos serviços de saúde, bem como problemas na regulação do Sistema, sem, entretanto, correlacionar tal situação ao subfinanciamento. Ao passo que, na entrevista seis é feita uma correlação entre as mudanças no acesso aos serviços a partir do congelamento de gastos, ou seja, o entrevistado atribui o que chama de "retrocessos" e dificuldades na oferta de serviços à redução do volume de recursos financeiros disponíveis devido a EC95.

\section{Visão dos conselheiros sobre a participação de sua entidade no CES e a atuação do segmento dos usuários}

Neste ponto, foram colocados aspectos que tanto dizem respeito à participação da entidade nos debates realizados nas reuniões do CES-BA como o seu posicionamento diante das pautas apresentadas no pleno e sua visão acerca da atuação do segmento dos usuários no conselho. No que tange tal participação, no ano de 2019, os conselheiros participaram das conferências municipais de saúde e atuaram na organização da conferência estadual de saúde do mesmo ano.

Para os entrevistados, a participação do segmento dos usuários mostrou-se expressiva, deixando evidente que os conselheiros estavam acompanhando as pautas e participando ativamente das plenárias. Apenas dois entrevistados citaram uma participação reduzida na gestão 2016-2018 devido a compromissos externos à sua função como conselheiros, que atrapalharam o acompanhamento das reuniões. $\mathrm{O}$ entrevistado 12 citou ter pouco tempo disponível para participar das discussões e incomoda-se pelas questões partidárias, considera que isso atrapalha o diálogo de opiniões divergentes:

O conselho tem aquelas coisas de levantar bandeira, mas é só fogo de palha, não vejo nenhuma pressão bem forte, eu acho que as ações deveriam ser mais dirigidas, mas lá é muita politicagem. Eu não sou dessa filosofia de ser contra só porque é de outro partido se realmente faz sentido, mas lá são tudo radicais... o pessoal que é do PT é contra, não quer nem saber, é contra. (E12)

No que diz respeito ao posicionamento das entidades no CES-BA acerca das pautas que surgiram no período, os representantes referiram que o segmento, de modo geral, se posicionou 
contrário às políticas danosas ao SUS, inclusive fazendo mobilizações.

o pensamento e a proposição é praticamente a mesma. Sempre de ser contrário as questões de acabar com o SUS, de privatizar o SUS. (E2)

Tem as pessoas que são divergentes $e$ convergentes, mas nesses dois últimos anos na questão das alterações seja ela muito mais a nível nacional a gente há concordância que isso está inviabilizando o SUS. (E1o)

O entrevistado cinco pontuou que, apesar das mobilizações em torno das pautas colocadas, as medidas não foram suficientemente efetivas, por não conseguirem mobilizar a população, considera que os esforços do conselho não foram suficientes para impedir o avanço dos desmontes.

o posicionamento das entidades do conselho foi um posicionamento firme, contrário inclusive apontando o quanto seria de prejuízo para a população. Mas também foi pouco eficaz. A gente se sentiu fragilizado. Pouco foi implementado, pouco foi ouvido. A gente elaborou documento que acabou não teve efeito real em nada. Foi pouca a capacidade de que a população estivesse de fato mobilizada, fazer que a população se sentisse atingida. $\left(\mathrm{E}_{5}\right)$

Quanto ao posicionamento geral do segmento dos usuários, há divergências, sobretudo, em relação às questões político-partidárias, que, em diversos momentos, assumiram centralidade no debate, impactando na dinâmica do CES. Um dos entrevistados comenta que tais divergências são agravadas devido a não compreensão por parte dos conselheiros do seu papel e por não haver entendimento do conteúdo das pautas quanto aos "ataques" ao SUS, o que gera, em sua opinião, um processo de desarticulação que favorece o pensamento dos “interessados" na não mobilização dos movimentos sociais.

Tem pouca divergência é mais assim com relação a conselheiros que ainda não estão bem esclarecidos quanto a seu papel. Às vezes, a entidade coloca a pessoa para estar ali representando no CES, mas ele não passou durante a sua vida por um processo de formação que dê condições de conhecimento a ele de chegar no ambiente como esse e saber de que forma ele vai se posicionar. (Е13)

Um desânimo entre as entidades de controle social, um desgaste muito grande, não nos unimos em determinadas pautas porque faltava compreensão do que estava para vir, do que estava sendo posto. (E6)

Além disso, muitas entidades usam o espaço do pleno para apresentar as demandas específicas do grupo que representa. Um dos conselheiros ressalta que os representantes deveriam pontuar os interesses do segmento dos usuários como um todo. Isso evidencia que a disputa por pautas específicas de interesse de cada entidade dificulta o debate e síntese das pautas de interesse comum do CES-BA, situação que se agrava quando conselheiros sequer defendem a pauta da sua entidade ou do segmento dos usuários, passando a defender pautas da gestão.

\section{Discussão}

Na composição do CES-BA fica nítida a força e diversidade de entidades de defesa de grupos de patologias que, apesar de existirem no cenário epidemiológico da população baiana, não são necessariamente as de maior expressão, o que deixa de fora a participação no CES-BA de grupos sociais que têm demandas e interesses específicos a defender, a exemplo de entidades da população LGBTQIA+, outras entidades religiosas, população quilombola, dentre outros. Essa situação não é exclusividade deste conselho, visto que a exclusão de entidades menos organizadas se verifica em outras instâncias participativas do SUS, como o CNS (Temoteo, 2016).

Diante de um processo democrático que permitiu a ascensão de representações de alguns movimentos a esta instância de gestão participativa do SUS-BA, cabe o questionamento do por que grupos expressivos no estado não conquistaram este local de poder, porquanto a diversidade ainda maior de entidades com direito à voz e voto enriqueceria o debate e proporcionaria a consideração de problemas e necessidades específicas 
dos diversos grupos no processo de formulação e implementação de políticas de saúde.

Nessa perspectiva, vale resgatar a análise de Labra (2012) da representação política nos conselhos, sobretudo no segmento dos usuários. A autora aponta que há uma infinidade de grupos que desejam participar, porém subsiste uma dificuldade de se definir "quem representa quem" (Labra, 2012, p. 241, tradução nossa) e de agrupar esse segmento com interesses tão difusos. Segundo a autora, tais questões variam de acordo com o local de atuação do conselho, a cultura política local e os critérios utilizados para se eleger um conselheiro. Neste ponto, são levadas em consideração diversas vezes a experiência acumulada do conselheiro no lugar do estímulo à renovação do pleno, acontecendo o que se chama de "profissionalização" (Labra, 2012) desses atores, que acabam reeleitos em decorrência da sua experiência mas também do seu grau de instrução e conhecimento das políticas de saúde.

Ainda com relação a esse aspecto, cabe problematizar que no CES-BA ocorre uma repetição de entidades na titularidade e suplência, o que, por um lado, pode ser bom para o alinhamento de ideias diante de pautas e para pleitear políticas específicas para tal grupo, por outro, significa uma redução na diversidade de entidades. Desta forma, reduz-se a chance de ampliar o debate no âmbito dos interesses coletivos, que é o maior objetivo das decisões dos conselhos. Em sua análise acerca da composição atual do CNS, Temoteo (2016) mostra uma problemática semelhante, explicitando que, quando isso acontece, costumam ser pautadas as mesmas questões já que titular e suplente têm a mesma bandeira de luta.

Diante disso, compreende-se a dificuldade desse segmento em formar um bloco político consistente, pois, diante da pluralidade de pautas específicas, produzem-se tensionamentos entre os representantes do próprio segmento dos usuários no conselho, dado que cada entidade se esforça para garantir o reconhecimento das demandas e das propostas específicas do seu grupo, apesar de haver bandeiras de luta em comum (Temoteo, 2016).

Ainda analisando o segmento dos usuários, Côrtes (2012) questiona o uso do termo usuário para designar este grupo dentro dos conselhos, pois eles não são apenas usuários dos serviços de saúde. Para a autora, o termo não dá conta das relações entre esses representantes e o Estado dentro do âmbito do conselho. Por isso, refere-se à existência de atores estatais e atores societais, sendo este último dividido entre os que representam o mercado e os que representam a sociedade civil. Tal perspectiva amplia o olhar, evidenciando o potencial de atuação e intervenção dentro do CES para além de usuários que desejam acesso a um serviço de saúde, entidades que se colocam como atores da sociedade civil em busca do direito à saúde e que estabelecem relações de paridade com o Estado dentro das plenárias.

Compreender esse segmento enquanto composto de atores societais permitiu analisar como eles se colocaram diante da conjuntura política do país, uma vez que 12 das 14 entidades entrevistadas posicionaram-se contra a EC95, participando de mobilizações pela sua revogação. De fato, com a aprovação da EC95 em 2016, ocorreu um agravamento do subfinanciamento do SUS, pois isso congelou os gastos do Governo Federal para as áreas sociais pelos próximos 20 anos. Cabe destacar os resultados de uma pesquisa realizada por Figueiredo et al. (2018) que analisou os gastos públicos e privados destinados à saúde no Brasil, Portugal, Espanha, Itália, França e Reino Unido no período 200o-2014, e evidencia que o Estado brasileiro (e não apenas um governo/partido) não tem priorizado o direcionamento dos gastos públicos para a saúde (e para o SUS). O Brasil foi o país que apresentou menor participação do gasto público em saúde e como percentual do PIB ( $46 \%$ e 3,8\% em 2014, respectivamente), no entanto, foi o que teve maior porcentagem do PIB destinado ao gasto privado em saúde $(4,5 \%)$. Fica evidente, portanto, o subfinanciamento crônico do SUS e a intensa expansão do setor privado na saúde, estimulada, inclusive, por incentivos fiscais do Governo Federal.

Medidas de austeridade similares à EC95 ocorreram nos períodos de recessão vivenciados na Europa, mas, ainda assim, os países da União Europeia destinavam cerca de $9 \%$ do seu PIB para a saúde (Figueiredo et al., 2018). Ademais, o contexto de recessão econômica nos países europeus levou as pessoas a classificarem sua saúde como pior e 
com agravamento dos indicadores de saúde mental, aumento dos suicídios e do número de pessoas em situação de rua, da mortalidade infantil e das desigualdades em saúde em geral (Opas, 2018).

No caso do Brasil, o congelamento dos investimentos terá um impacto negativo sobre a saúde da população, que já vem apresentando, como tendência, o aumento da proporção de idosos, com consequente aumento da prevalência de doenças crônico-degenerativas, além do aumento da morbimortalidade por câncer, no número de acidentes e violências, a prevalência de adoecimento mental e desdobramentos à longo prazo das epidemias de Zika e Chikungunya (Teixeira; Paim, 2018).

Simulações prospectivas sobre os efeitos da EC95 alertaram para a possível piora dos indicadores de saúde sobretudo em um país onde as desigualdades já são exacerbadas (Rasella et al., 2019), chama a atenção que o impacto negativo seria maior entre a parcela pobre e negra da população. Nesse sentido, o "Relatório: 30 anos de SUS, que SUS para 2030?" (Opas, 2018) enfatiza que a aprovação da EC95 e alterações em políticas de saúde específicas devem agravar a situação de saúde da população.

Quanto às mobilizações em torno da EC95, destacase o desânimo pontuado pelos conselheiros, pois as ações realizadas pelos mesmos (manifestações em Brasília, abaixo-assinado, entrada com Ação Direta de Inconstitucionalidade, documentos elaborados...) não tiveram uma repercussão a ponto de mudar as decisões do Governo. Segundo Labra (2012), essa frustação frente a um esforço costuma ocorrer entre os conselheiros, gerando preocupações, pois as deficiências do SUS e as dificuldades dentro do contexto da saúde incidem diretamente sobre o compromisso com os processos participativos.

Por fim, vale ressaltar que divergências políticopartidárias foram percebidas pelos conselheiros como fatores que atrapalham/dificultam na convergência de propostas para um posicionamento conjunto diante das pautas no CES-BA. Essa percepção, entretanto, é controversa, na medida em que autores como Gerschman (2004) defendem que a função dos conselheiros não diz respeito apenas à defesa de interesses individuais e de grupos, e que a ausência de organizações políticas que elaboram projetos de sociedade esvazia o sentido dos conselhos. Ainda que não formalmente representados, entretanto, cabe sinalizar, de acordo com o estudo de Santos et al. (2015), que a influência dos partidos políticos molda a direção do processo político nos conselhos, ditando os rumos das políticas de saúde.

\section{Considerações finais}

A análise do posicionamento do segmento dos usuários nos permite concluir que os representantes que compõem esse segmento, embora não apresentem uma visão aprofundada e consistente da crise e do desmonte do SUS, tendem a posicionar-se em defesa do SUS constitucional, opondo-se às medidas do Governo Federal, especialmente no que diz respeito à redução dos recursos financeiros do SUS e perdas de direitos conquistados. A forma como todo esse contexto político foi visto, porém, ainda é superficial, pois alguns conselheiros admitem o pouco conhecimento acerca das reais consequências do que estava sendo posto pelo Governo Federal e a reduzida compreensão do papel do CES-BA.

É preciso considerar que estes conselheiros possuem um saber construído através da sua experiência (Valla, 1996) que subsidia sua atuação no CES-BA, possibilitando a construção de suas análises e posicionamentos acerca do SUS que partem de pontos diferentes do saber técnico, mas tão potentes quanto. Assim, a média de tempo no CES-BA (seis anos), por vezes vista como "profissionalização", pode também ser vista como positiva já que com o passar dos anos o acúmulo de experiência pode torná-los tão capazes quanto os representantes dos outros segmentos. Ainda que alguma capacitação técnica seja necessária (sobretudo, quando não há experiência acumulada), a experiência e o conhecimento dos projetos políticos em disputa, tanto no âmbito mais geral quanto no campo da Saúde, podem ser os elementos mais importantes para qualificar e potencializar a atuação dos representantes dos usuários nos conselhos de saúde.

Nesse sentido, consideramos importante que a atuação dos conselheiros não se limite à discussão das pautas do conselho, definidas, no mais das vezes, em função dos interesses dos gestores e de outros 
segmentos lá representados, cabendo, portanto, aos conselheiros a interlocução constante com as bases sociais que representam, de modo a traduzir suas necessidades e demandas em propostas concretas que possam ser articuladas com projetos mais amplos de mudança social e, especificamente, da defesa do direito universal à saúde e do SUS.

\section{Referências}

BARDIN, L. Análise de conteúdo. São Paulo: Almedina, 2011.

BRASIL. Lei no 8.08o, de 19 de setembro de 1990. Dispõe sobre as condições para a promoção, proteção e recuperação da saúde, a organização e o funcionamento dos serviços correspondentes. Diário Oficial da União, Brasília, DF, 19 set. 199oa. Disponível em: <https://bit.ly/3cECO 7 E $>$.

Acesso em: $1^{0}$ dez. 2018.

BRASIL. Lei no 8.142, de 28 de dezembro de 1990. Dispõe sobre a participação da comunidade na gestão do Sistema Único de Saúde (SUS) e sobre as transferências intergovernamentais de recursos financeiros na área da saúde. Diário Oficial da União, Brasília, DF, 28 dez. 199ob. Disponível em: <https://bit.ly/390QqeJ>. Acesso em: $1^{\circ}$ dez. 2018.

BRASIL. Ministério da Saúde. Portaria nº 545, de 20 de maio de 1993. Estabelece normas e procedimentos reguladores do processo de descentralização da gestão das ações e serviços de saúde. Diário Oficial da União, Brasília, DF, 20 maio 1993. Disponível em:

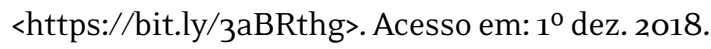

BRASIL. Ministério da Saúde. Portaria nº 2.203, de 5 de novembro de 1996. Redefine o modelo de gestão do Sistema Único de Saúde. Diário Oficial da União, Brasília, DF, 5 nov. 1996. Disponível em: <https://bit.ly/3rPcpZu>. Acesso em: $1^{\circ}$ dez. 2018.

BRASIL. Ministério da Saúde. Resolução nº 453, de 10 de maio de 2012. Aprova as diretrizes para instituição, reformulação, reestruturação e funcionamento dos Conselhos de Saúde. Diário Oficial da União, Brasília, DF, 10 maio 2012. Disponível em: <https://bit.ly/2MVRPqQ>. Acesso em: 15 out. 2019.
BRASIL. Lei no 13.429, de 31 de março de 2017. Altera dispositivos da Lei $n^{0}$ 6.019, de 3 de janeiro de 1974, que dispõe sobre o trabalho temporário nas empresas urbanas e dispõe sobre as relações de trabalho na empresa de prestação de serviços a terceiros. Diário Oficial da União, Brasília, DF, 31 mar. 2017a. Disponível em: <https://bit.ly/3jcgZgV>. Acesso em: 10 set. 2019.

BRASIL. Lei no 13.467 , de 13 de julho de 2017. Altera a Consolidação das Leis do Trabalho (CLT). Diário Oficial da União, Brasília, DF, 13 jul. 2017b. Disponível em: <https://bit.ly/3aydoHh>. Acesso em: 10 set. 2019.

CARVALHO, A. I. Conselhos de saúde no Brasil: participação cidadã e controle social. Fase/Ibam, Rio de Janeiro, p. 136, 1995.

CÔRTES, S. M. V. Consejos y conferencias de salud: el papel institucional y los cambios em las relaciones entre Estado y sociedad. In: FLEURY, S.; LOBATO, L. V. C. (Coord.). Participación, democracia y salud. Buenos Aires: Lugar Editorial, 2012. v. 1, p. 125-157.

COSTA, A. M.; NORONHA, J. C. Controle social na saúde: construindo a gestão participativa. Saúde em Debate, Rio de Janeiro, v. 27, n. 65, p. 358-363, 2003.

DOMINGUEZ, B. Hospitais psiquiátricos: nunca mais? Radis Comunicação e Saúde, Rio de Janeiro, 30 jan. 2018. Disponível em: <https://bit.ly/ 39I9LOj>. Acesso em: 10 set. 2019.

FIGUEIREDO, J. O. et al. Gasto público e privado com saúde no Brasil e países selecionados. Saúde em Debate, Rio de Janeiro, v. 42, n. 2, p. 37-47, 2018.

GERSCHMAN, S. Conselhos municipais de saúde: atuação e representação das comunidades populares. Caderno de Saúde Pública, Rio de Janeiro, v. 20, n. 6, p. 1670-1681, 2004.

GOVERNO e planos de saúde querem reformulação do SUS com privatização do atendimento à população. Universidade Federal do Mato Grosso, Cuiabá, 17 abr. 2018. Disponível em: <https://bit.ly/ 3pNszRQ>. Acesso em: 15 set. 2019.

LABRA, M. E. Política nacional de participación en salud: entre la utopía democrática del control 
social y la praxis predatoria del clientelismo empresarial. In: FLEURY, S.; LOBATO, L. V. C. (Coord.). Participación, democracia y salud. Buenos Aires: Lugar Editorial, 2012. v. 1, p. 221-253.

MIGUEL, L. F. A democracia na encruzilhada. In: JINKINGS, I.; DORIA, K.; CLETO, M. (Org.). Por que gritamos golpe? Para entender o impeachment $\mathrm{e}$ a crise política no Brasil. São Paulo: Boitempo, 2016. p. 31-37.

NORONHA, J. C. et al. Notas sobre o futuro do SUS: breve exame de caminhos e descaminhos trilhados em um horizonte de incertezas e desalentos.

Ciência \& Saúde Coletiva, Rio de Janeiro, v. 23, n. 6, p. 2051-206o, 2018.

OAPS - OBSERVATÓRIO DE ANÁLISE POLÍTICA EM SAÚDE. A quem interessa a nova Política Nacional de Atenção Básica? Boletim OAPS, Salvador, ano 3, n. 13, 2017. Disponível em: <https://bit.ly/39LDTIK>. Acesso em: 10 set. 2019. OPAS - ORGANIZAÇÃO PAN-AMERICANA DA SAÚDE. Relatório 30 anos de SUS, que SUS para 203o? Brasília, DF, 2018.

PAIM, J. S. Sistema Único de Saúde (SUS) aos 30 anos. Ciência \& Saúde Coletiva, Rio de Janeiro, v. 23, n. 6, p. 1723-1728, 2018.

RASELLA, D. et al. Mortality associated with alternative primary healthcare policies: a nationwide microsimulation modelling study in Brazil. BMC Medicine, London, v. 17, n. 1, art. 82, 2019.

REIS, V. Nota Abrasco: sobre a saída dos médicos cubanos do Mais Médicos. Abrasco, Rio de Janeiro, 18 nov. 2018. Notícias. Disponível em: <https://bit.ly/ 39IhfRq $>$. Acesso em: 10 set. 2019.

ROCHA, R. Governo corta Bolsa Família de quase 1 milhão de famílias. CUT Brasil, São Paulo, 4 maio 2018. Notícias. Disponível em: <https://bit.ly/ 2MvıyEx>. Acesso em: 10 set. 2019.

SANTOS, F. A. et al. A definição de prioridade de investimento em saúde: uma análise a partir da participação dos atores na tomada de decisão. Physis: Revista de Saúde Coletiva, Rio de Janeiro, v. 25 , n. 4, p. 1079-1094, 2015.
TEIXEIRA, C. F. S.; PAIM, J. S. A crise mundial de 2008 e o golpe do capital na política de saúde no Brasil. Saúde em Debate, Rio de Janeiro, v. 42, n. 2, p. 11-21, 2018.

TEMOTEO, B. Composição atual do Conselho Nacional de Saúde: questões para debate.

Observatório de Análise Política em Saúde, Salvador, 21 mar. 2016. Pensamentos. Disponível em: <https://bit.ly/3oFyerW>. Acesso em: 17 jan. 2019.

TORRES, R.; REIS, V. A quem interessam os planos de saúde "populares"? Abrasco, Rio de Janeiro, 22 set. 2016. Notícias. Disponível em: <https://bit.ly/ 3cCQnnT>. Acesso em: 10 set. 2019.

VALLA, V. V. A crise de interpretação é nossa: procurando compreender a fala das classes subalternas. Educação \& Realidade, Porto Alegre, v. 21, n. 2, p. 177-19o, 1996.

VIRGENS, J. H. A.; SILVEIRA, P. Análise do processo da reforma sanitária brasileira no período de 2007 a 2016: participação social em 2016. In: OBSERVATÓRIO DE ANÁLISE POLÍTICA EM SAÚDE (Org.). Relatório de acompanhamento de políticas. Salvador, 2016. p. 1-14.

\section{Agradecimentos}

Ao Conselho Estadual de Saúde da Bahia, que aceitou e colaborou com a realização desta pesquisa, em especial à Mesa Diretora e aos conselheiros que compuseram o segmento dos usuários na gestão 2016-2018.

\section{Contribuição das autoras}

Morais concebeu o trabalho, realizou a pesquisa de campo e redigiu o artigo. Teixeira orientou e fez a revisão final.

Recebido: 10/08/2020

Aprovado: 09/09/2020 